\title{
Benign Breast Tumours - Diagnosis and Management
}

\author{
Stefan Paepke ${ }^{a, b, c}$ Stephan Metz $^{d}$ Anika Brea Salvago ${ }^{e}$ Ralf Ohlinger ${ }^{e}$ \\ ${ }^{a}$ Department of Obstetrics and Gynecology, Technical University of Munich, Munich, Germany; \\ ${ }^{\mathrm{b}}$ Roman Herzog Comprehensive Cancer Center, Munich, Germany; \\ ${ }^{\mathrm{c}}$ Comprehensive Cancer Center München, Munich, Germany; \\ dDepartment of Radiology, Technical University of Munich, Munich, Germany; \\ e Department of Gynecology and Obstetrics, Ernst-Moritz-Arndt University Greifswald, Greifswald, Germany
}

\section{Keywords}

Benign breast tumours - Overview · Imaging features . Minimally invasive diagnostics · Therapy

\section{Summary}

With improvements in breast imaging, mammography, ultrasound and minimally invasive interventions, the detection of early breast cancer, non-invasive cancers, lesions of uncertain malignant potential, and benign lesions has increased. However, with the improved diagnostic capabilities comes a substantial risk of false-positive benign lesions and vice versa false-negative malignant lesions. A statement is provided on the manifestation, imaging, and diagnostic verification of isolated benign breast tumours that have a frequent manifestation, in addition to general therapy management recommendations. Histological evaluation of benign breast tumours is the most reliable diagnostic method. According to the S3 guideline and information gained from analysis of the literature, preference is to be given to core biopsy for each type of tumour as the preferred diagnostic method. An indication for open biopsy is also to be established should the tumour increase in size in the follow-up interval, after recurring discrepancies in the vacuum biopsy results, or at the request of the patient. As an alternative, minimally invasive procedures such as therapeutic vacuum biopsy, cryoablation or high-intensity focused ultrasound are also becoming possible alternatives in definitive surgical management. The newer minimally invasive methods show an adequate degree of accuracy and hardly any restrictions in terms of postinterventional cosmetics so that current requirements of extensive breast imaging can be thoroughly met.

(c) 2018 S. Karger GmbH, Freiburg

\section{Introduction}

With improvements in breast imaging, mammography, ultrasound and minimally invasive interventions, the detection of early breast cancer, non-invasive cancers, lesions of uncertain malignant potential, and benign lesions has increased. However, with the improved diagnostic capabilities comes a substantial risk of false-positive benign lesions and vice versa false-negative malignant lesions.

Whereas 'Imaging Report and Data System' (BI-RADS) lesions classified in Group 2 as definitely benign in mammography terms require no further clarification, it is recommended that cases of tumours that are classified as BI-RADS Group 3 in mammography terms should be subjected to a shorter follow-up interval or biopsy in view of their unclear malignant potential [1]. Benign breast tumours include both lesions classified as BI-RADS 2 (such as lipomas) and tumours classified as BI-RADS 3 (such as phyllodes tumours) [2]. A statement is provided on the manifestation, imaging, and diagnostic verification of isolated benign breast tumours that have a frequent manifestation, in addition to general therapy management recommendations.

\section{Papillomas}

Papillomas (first described by Warren in 1905 [3]) are found in around $1-3 \%$ of all biopsy tissue samples taken from the breast [4, 5] (figs. 1,2). The relevance of milk duct papillomas is not to be underestimated despite this relatively low incidence, as they are deemed to be a risk factor for malignant processes regardless of whether it is a solitary or a multiple manifestation. In pathogenetic terms, the development of papillomas can be explained by a reversal of the proliferation direction. Whereas a mesenchymal induction occurs in all hyperplasias, with papillomas, a strong epithelial autonomy results in the formation of free epithelial masses that then set themselves apart in the mesenchymal proliferation.

\section{KARGER}

() 2018 S. Karger GmbH, Freiburg

Fax +497614520714 
1

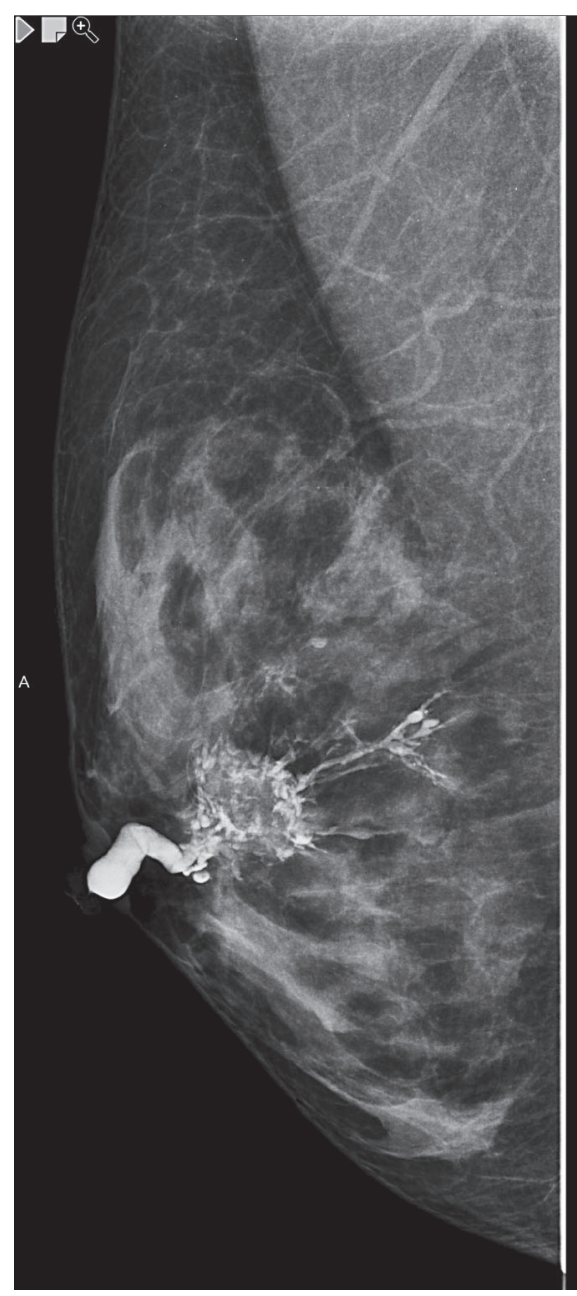

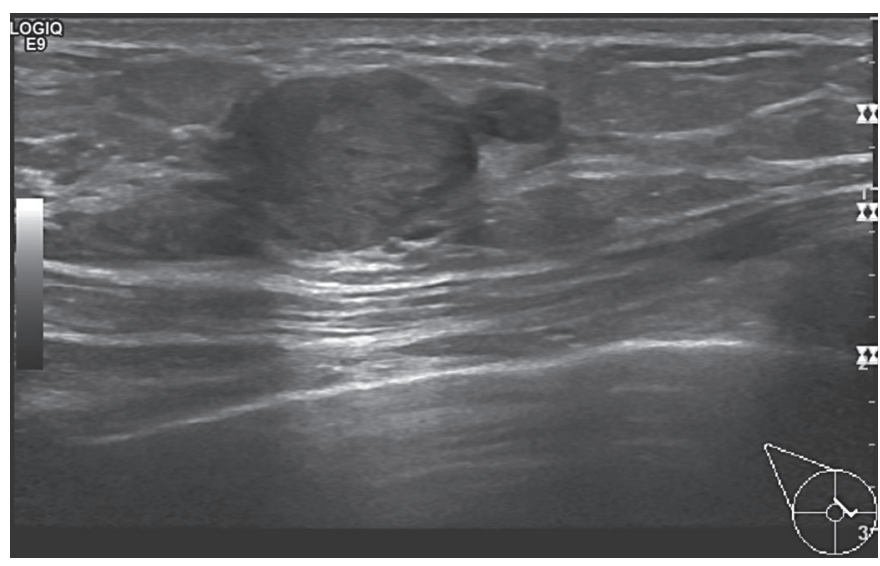

Fig. 1. Intraductal papilloma - galactography.

Fig. 2. Sonographic presentation of a papilloma.

in perimenopausal females [11]. As longitudinal-oval tumours, they generally have a diameter of under $0.5 \mathrm{~cm}$ with a maximum length of 4-5 cm [12]. Multiple intraductal papillomas account for around $10 \%$ of all intraductal papillomas. Compared to solitary papillomas, the manifestation is most likely in younger patients and more frequently bilateral. Multiple intraductal papillomas are also less likely to cause milk duct secretion. Papillomas frequently cause serosanguinous milk duct secretion [6] and $80-100 \%$ of cases present with secretion or bleeding from the nipple. In this context, secretion is a clinical symptom of solitary central papillomas in $64-88 \%$ of all cases, whereby this is only $25-35 \%$ of all cases of multiple peripheral papilloma [13].

\section{Non-Invasive Diagnostics}

Palpation

A tumour can be palpated in $11-57 \%$ of cases of solitary papil-

The papilloma group comprises [6]:

- intraductal solitary papilloma

- intraductal multiple papilloma

- papillomatosis

- juvenile papillomatosis.

The differentiation is made on the basis of the intraductal distribution of the papillomas, with solitary papillomas finding their genesis in the large, segmental, and subsegmental efferent ducts and multifocal localised papillomas originating from the terminal duct lobular units [7]. Papillomatosis is defined as a minimum of 5 papillomas that are clearly separated from each other within a restricted segment of the breast tissue [8]. Juvenile papillomatosis is a neoplasia that effects young females and is characterised by an atypical papillary ductal hyperplasia and numerous cystic formations. This disease is associated with an increased risk of breast cancer $[9,10]$.

\section{Clinic}

Age at Manifestation, Size, and Prevalence

Intraductal solitary papillomas have a prevalence of $1.8 \%$ of all mammary tumours, and the manifestation is typically identifiable loma. The detected mass is normally a widened milk duct in which the papilloma is able to extend and cause an obstruction.

\section{Mammography}

Intraductal papillomas are not normally detected on mammography due to their small size and the typical location in the central and more compact regions of the breast. Mammographic images related to papillomas include circumscribed retroaleolar nodes that have a benign appearance, a solitary retroaleolar widened milk duct, and seldom microcalcifications $[14,15]$. Some papillomas can cause sclerosis with the result that the subsequent calcification presents as coarsely flocculated, shell-shaped, or punctiform intraductal calcifications that extend along the milk duct (fig. 2).

\section{Ultrasound}

Intraductal papillary neoplasias show different ultrasound presentations depending on their macroscopic appearance. A characteristic feature of papilloma is however a widened milk duct with an intraductal round focus or a cyst with an intracystic solid structure [16] (fig. 2). According to Han et al. [17], intraductal neopla- 
sias are subdivided into 4 categories based on their relationship to the milk duct in the ultrasound examination:

- Type 1: intraluminal mass

- Type 2: extraductal mass

- Type 3: simple solid mass

- Type 4: a combination (fig. 2).

The use of sonographic elastography in combination with conventional ultrasound can improve specificity when it comes to differentiating between benign or atypical or malignant papillary breast lesions [18].

\section{MRI}

Intraductal papillomas can present differently on magnetic resonance imaging (MRI) examination. Findings include concealed formations, small luminal structures, or irregular fast growing lesions that cannot be differentiated from invasive malignomas. High costs, limited clinical experience, and suboptimal specificity restrict the use of MRI in this context [19-21].

\section{Minimally Invasive Diagnostics}

Based on minimally invasive biopsy, intraductal papillomas are classified as B3 lesions in histopathological terms (lesions of unclear biological potential) [22-26].

\section{$\mathrm{CB}$}

Core biopsy $(\mathrm{CB})$ has restrictions similar to those of fine needle aspiration cytology (FNAC). There is therefore a general consensus with regard to surgical excision being required for papillomas with atypical features verified by CB [27-32].

\section{$\mathrm{VAB}$}

Should intraductal papillomas be detectable on mammography and/or ultrasound, a vacuum biopsy (VAB) can be used for both diagnostic and therapeutic purposes. This minimally invasive method provides secure and accurate tissue analysis and, with a high degree of possibility, can remedy symptoms in patients suffering from nipple discharge [33].

\section{Ductoscopy}

Ductoscopy is an endoscopic technique to examined and evaluated the interior of pathologically secreting milk ducts [34]. The ductoscope can at the same time be used for insufflation, duct lavage, or therapeutic interventions [35]. The use of cytology brushes, small baskets, or microbiopsy forceps ensures targeted sampling. In ductoscopic terms, normal milk duct epithelium is of a pale yellow to pink colour and can have annular folds on the duct wall. Ductoscopy has the advantage that an exact localisation of the pathological finding is possible, ductal lavage can be conducted under direct observation, and intraoperative control is also possible, especially where there is a manifestation of lesions deep within the milk duct system [36]. However, this method only plays a restricted role as it does not provide access to the terminal duct lobular units that are often the origin of malignant lesions. The ductoscopic appearance of intraductal papillomas can range from red to yellow to ashen [37]. Papillomas can extend into the lumen of the milk duct as a polypoid mass where they present as solitary or multiple lesions - a benign mammary tumour in a single milk duct system. In rare cases, papillary lesions can occur in different milk duct systems, both unilateral and bilateral [37].

\section{Therapy}

The decision concerning a suitable therapy for intraductal papilloma can be challenging due to the difficult differentiation between intraductal papilloma and carcinoma. Surgical excision is generally recommended in patients with peripheral multiple intraductal lesions and atypical papillomas that are diagnosed based on intraductal breast biopsy [38]. Younger patients with nipple discharge from only 1 milk duct can be successfully treated with a minimal surgical intervention in the form of a microreductomy. In older patients, a radical milk duct excision can be of benefit even if the secretion originates from only 1 milk duct. This gives the opportunity to avoid discharge from other milk ducts and obtain a complete histology.

In keeping with the recommendations made by the Arbeitsgemeinschaft Gynäkologische Onkologie e.V. (AGO Breast Committee, 2018 [38]), no additional measures need to be adopted if papillomas are verified by $\mathrm{CB}$ or $\mathrm{VAB}$ findings that are not atypical, provided the biopsy material is representative $\left(100 \mathrm{~mm}^{2}\right)$ and findings are consistent. No data currently exists regarding the procedure to be adopted in cases where there is evidence of papilloma in the edges of the resected tissue [39].

\section{Prognosis}

The risk of an invasive carcinoma developing in the future in patients with intraductal papilloma (atypical or not) should be evaluated based on the surrounding breast tissue. A benign solitary papilloma without any changes to the surrounding breast tissue indicates only a slightly increased risk of invasive mammary carcinoma developing in the future $[38,39]$. The relative risk posed by peripheral papillomas can be higher than with central papillomas. Carcinoma risk is based on the ductal and atypical hyperplasias that render the development of carcinoma in the terminal duct lobular units probable in $12 \%$ of cases. Recurrences occur in $23 \%$ of cases. Papillomas indicate an increased risk of formation of an ipsilateral carcinoma. The percentage rates for atypical papillomas are between 4.6 and $13 \%$. Juvenile papillomatosis appears to be associated with an increased risk of breast cancer simultaneously or in the future [40]. No data currently exists regarding the therapeutic procedure in cases where there is evidence of papilloma in the edges of the resected tissue. Excision should be carried out in the case of juvenile papillomatosis. Close monitoring does not suffice [41].

\section{Mixed Fibroepithelial Tumours}

\section{Fibroadenomas}

Fibroadenomas are benign biphasic tumours that originate from the terminal duct lobar units as localised tumours and display 

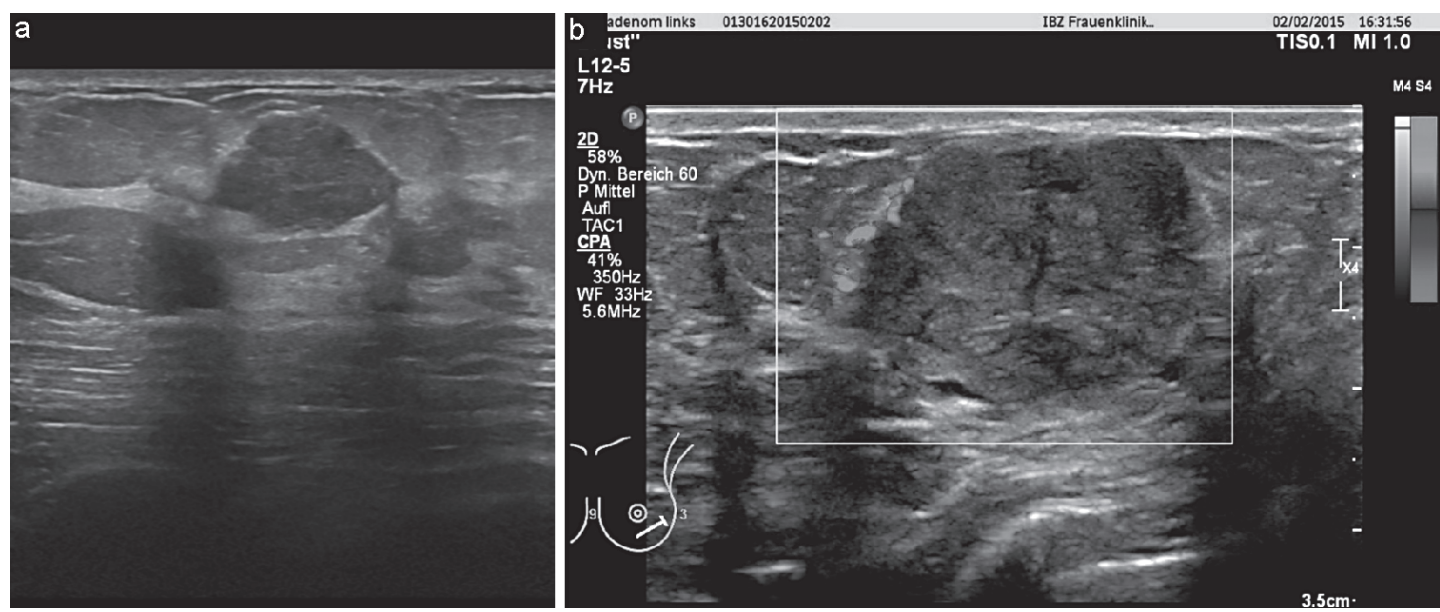

Fig. 3. a, b Fibroadenoma - sonographic findings.

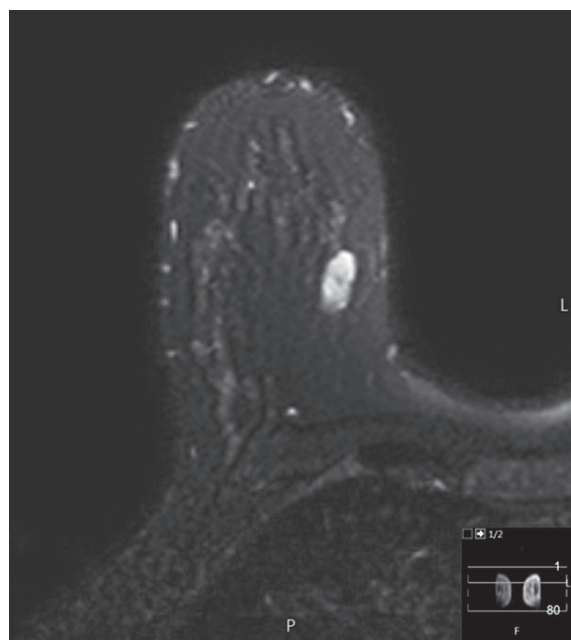

Fig. 4. Fibroadenoma - MRI-findings $T 2$-fs sequence; signal intense.

proliferation of the epithelial and fibrous tissue components (figs. $3,4)[42,43]$.

\section{Pathogenesis}

It is assumed that fibroadenomas are the result of abnormal proliferation and involution of the breast tissue due to hormonal influences and that they do not present a 'real' neoplasia [44].

\section{Terminology}

Fibroadenomas are subdivided into [45]:

- adult fibroadenomas that typically manifest in young females

- juvenile fibroadenomas that exist during puberty and in adolescents.

\section{Clinic}

Age at Manifestation, Size, and Prevalence

After carcinomas, fibroadenomas are the second most-prevalent neoplasia of the female breast and the most prevalent tumour in females aged under 30 [46]. Their prevalence is reduced to a great extent in the postmenopausal period. The average size is between 1 and $3 \mathrm{~cm}$ [45].

\section{Non-Invasive Diagnostics}

Palpation

Fibroadenomas present as painless, solitary, solid, smoothly demarcated, slow-growing, and movable nodes.

\section{Mammography}

Fibroadenomas normally present on mammography as smooth circumscribed lesions; however, $25 \%$ of tumours can include features suspicious for malignancy. Characteristic aspects are complete or almost complete calcification of the fibroadenoma that can have a shell-shaped, popcorn-like, bizarre, or bowl-like form. In the case of pericanalicular fibroadenomas, the calcifications can take a linear, $y$, or $\mathrm{v}$ form. Calcifications in intracanalicular fibroadenomas tend to be rather round or fine-punctiform [47-49].

\section{Ultrasound}

The classic fibroadenoma has the following ultrasound characteristics [50]:

- an elliptical or slightly lobulated form

- greater elongation in the transversal and craniocaudal image than in the anterior-posterior image

- isoreflective to hyporeflective echotexture when compared with fatty tissue

- completely surrounded by a fine echogenous capsule

- normal or accentuated sonic transmission when compared with the surrounding tissue

- fine boundary shadows

- unrestricted movement during palpation

- easily compressed. 


\section{MRI}

Fibrosed fibroadenomas uptake only a small quantity of contrast medium or none at all. If a non-cystic tumour presents without any uptake, a T2-weighted pulse sequence should be performed in order to exclude mucinous carcinoma. A fibrous fibroadenoma can therefore be assumed should the signal intensity in the T2weighted sequence be low. Fibroadenomas with a high water or cell content have a considerable mostly slow but sometimes also fast uptake of the contrast medium and show a smoothly demarcated, oval, and lobulated appearance with low-signal septa. However, peripheral enhancement does not indicate the existence of a fibroadenoma [49].

\section{Minimally Invasive Diagnostics}

$\mathrm{CB}$

In the diagnosis of fibroadenoma, $\mathrm{CB}$ has the benefit of being able to detect complex changes and epithelial proliferations more easily than FNAC $[48,50,51]$.

\section{$\mathrm{VAB}$}

$\mathrm{VAB}$ can be a safe and successful alternative when it comes to treating fibroadenomas. In addition to the diagnostic benefits, VAB has therefore also gained importance as a minimally invasive therapeutic method $[52,53]$.

\section{Therapy}

It is assumed that fibroadenomas grow over a period of 12 months, increasing in size by around $2-3 \mathrm{~cm}$ before remaining unchanged for a number of years. It is also assumed that fibroadenomas tend to regress and lose cell mass the older they become [54]. Should a CB examination therefore detect a fibroadenoma, conservative management with close ultrasound follow-up after 6,12 , and 24 months should be attempted $[55,56]$. An increase in the size of the fibroadenoma within this interval or the occurrence of symptoms caused by the tumour should serve as an indication for excision biopsy. As the post-interventional cosmetic result plays an important role with benign breast tumours, tumour extirpation is increasingly being carried out using minimally invasive therapeutic procedures as described below [53].

\section{$\mathrm{VAB}$}

$\mathrm{VAB}$ is an efficient and cost-saving therapeutic procedure with good cosmetic results that is becoming increasingly popular and has developed into the standard management method for the treatment of benign breast tumours. Disadvantages are the probability of recurrence and the possibility that the tumour is not fully extirpated. Complete excision and maximum cosmetic outcome can be achieved with a tumour size of under $3 \mathrm{~cm}$ as a standard $[57,58]$.

\section{Cryoablation}

This is a method that is almost painless and can be used for superficial lesions. It is therefore the preferred option for patients wishing to have their fibroadenoma treated without surgical inter- vention. This therapeutic method is deemed to be an effective and safe way of reducing the size and symptoms of the fibroadenoma while achieving excellent cosmetic results. When compared with $\mathrm{VAB}$, it was not possible to detect any recurrences. The analgesic effect of the cold, the procedure-related lack of any changes being discernible on mammographic examination conducted at a later date, and the positive immunostimulatory effect are all deemed to be beneficial [59-62].

\section{High-Intensity Focused Ultrasound}

High-intensity focused ultrasound (HIFU) is a non-invasive method in which a concentrated ultrasound bundle penetrates and heats the tissue exerting a regional effect. When compared with cryoablation and radiofrequency ablation, this has the advantage that the tissue that is to be destroyed is exactly adapted to the form of the tumour $[63,64]$. As this is one of the latest therapeutic methods for the treatment of fibroadenomas, a large number of clinical trials are currently being conducted with regard to its effectiveness.

\section{Prognosis}

The breast cancer risk in breasts containing or pretreated for fibroadenomas is low, even if a slightly increased risk has been observed [65]. Cases where fibroadenomas have transformed into malignant phyllodes tumours are described in the literature [66, 67]. There is an increased risk of malignant degeneration in cases with proliferative changes in the breast parenchyma adjacent to the fibroadenoma or in females with complex fibroadenomas and a positive family history of breast cancer [68]. The majority of fibroadenomas do not recur after complete surgical excision. In younger women, there is a tendency to develop 1 or more new lesions either at the surgical site or in other parts of the body.

\section{Phyllodes Tumour}

Phyllodes tumours (described for the first time by Johannes Muller in 1838 [69]) are rare breast neoplasias that only account for $0.3-1 \%$ of all mammary tumours $[70,71]$.

\section{Terminology}

Due to its cystic components and fleshy appearance, this tumour was originally referred to as 'cystosarcoma'. However, taking into account that these tumours display benign behaviour in the majority of the cases, the World Health Organisation recommended the use of the neutral expression 'phyllodes tumour' [72].

\section{Pathogenesis}

The pathogenesis of phyllodes tumours is still not clear. In addition to a de novo genesis in the breast parenchyma, emergence from existing fibroadenomas or malignant transformation of a fibroadenoma after radiotherapy are also discussed. Growth-stimulating factors of phyllodes tumours include trauma, lactation, pregnancy, and elevated oestrogen levels [73]. 


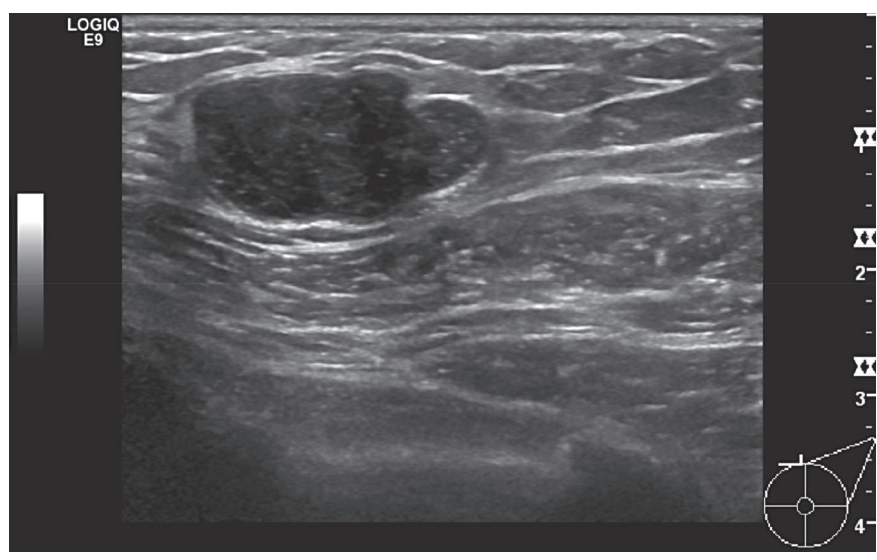

Fig. 5. Ultrasound image of a phyllodes tumour in the left breast - sonographic findings.

\section{Clinic}

Age at Manifestation, Size, and Frequency

In Western countries, phyllodes tumours account for $2.5 \%$ of all fibroepithelial breast tumours. The prevalence is predominantly in middle-aged females (incidence peak between age 40 and 50 years). The mean size is $4-5 \mathrm{~cm}$ [74].

\section{Microscopy}

The histological picture of the phyllodes tumour resembles that of the intracanalicular fibroadenoma. Longitudinal ductal sections are discernible together with a papillary protuberance of the connective tissue, resulting in the tumour having a leaf-like appearance. The existence of epithelial and connective tissue elements is necessary in order to establish the diagnosis. The stroma hereby represents the neoplastic components and determines the pathological behaviour of the tumour. Only the stroma cells are able to metastasise. The histological differentiation between phyllodes tumour and fibroadenoma is based on the proof of the existence of a stroma with a greater number of cells and mitotic activity. Phyllodes tumours are classified as benign, borderline, or malignant depending on their histological characteristics $[75,76]$.

\section{Immunohistology}

Immunohistochemical tests have proven the benefit of CD10 expression in differentiating between benign and other forms of phyllodes tumour in addition to estimating the manifestation of distant metastases in connection with mammary phyllodes tumours [77].

\section{Non-Invasive Diagnostics}

Palpation

Phyllodes tumours normally present as fast-growing but clinically benign tumours and are frequently located in the upper outer quadrants with a homogenous distribution in both breasts. The skin above larger tumours can show dilated veins and be of a blue colour; nipple retraction is rare. Palpable axillary lymphadenopathy can be detected in up to $20 \%$ of patients, but this is seldom the case with regard to lymph node metastases.

\section{Mammography}

On mammography, phyllodes tumours present as smoothly demarcated structures with a smooth and partially lobulated edge [78-86]. A radiotranslucent ring that results from the compression of the surrounding mammary connective tissue can be discerned around the structure [87].

\section{Ultrasound}

On ultrasound examination, phyllodes tumours present as solid, smoothly demarcated, and lobulated space-occupying lesions that can include cystic components. However, a reliable differentiation between benign and malignant forms is not possible by ultrasound [88, 89] (fig. 5).

\section{MRI}

The existence of a phyllodes tumour is to be assumed if the following are discernible in the MRI evaluation [90]:

- large structure with a smoothly demarcated edge

- heterogeneous appearance in the T2-weighted sequence

- hyperintense spaces in the T2-weighted fat-saturated and STIR sequences that are filled with fluid

- rapid contrast medium uptake in dynamic imaging without existence of a washout phenomenon

\section{Minimally Invasive Diagnostics}

\section{$\mathrm{CB}$}

The interdisciplinary S3 Guidelines for the Diagnostic, Therapy and Aftercare of a Mammary Carcinoma recommend classification as 'B3' should the punch or vacuum biopsy provide indications for the existence of a phyllodes tumour. In view of the fact that the differentiation from fibroadenoma is impossible, the term 'fibroepithelial tumour' should be used in order to avoid a false diagnosis (and in turn an undervaluation of the phyllodes tumour) [91, 92]. Although tissue biopsy errors can occur with $\mathrm{CB}$, the selective use of $\mathrm{CB}$ is an attractive option when it comes to improving the preoperative diagnosis of phyllodes tumours.

\section{$\mathrm{VAB}$}

Only restricted statements on the use of VAB with phyllodes tumours can be found in the current literature. The preoperative diagnosis of phyllodes tumours can be improved by a more frequent use of $\mathrm{VAB}$ and $\mathrm{CB}[93]$.

\section{Therapy}

Local or wide excision is deemed to be the preferred method when treating benign phyllodes tumours. Recurrence of borderline lesions and malignant phyllodes tumours can be reduced by wide excision with tumour-free margins. Diagnostic local excision biopsies or tumour enucleations should be followed up with a definitive wide excision [93]. An annual ultrasound postoperative follow-up examination is generally recommended due to the risk of recurrence. 
6

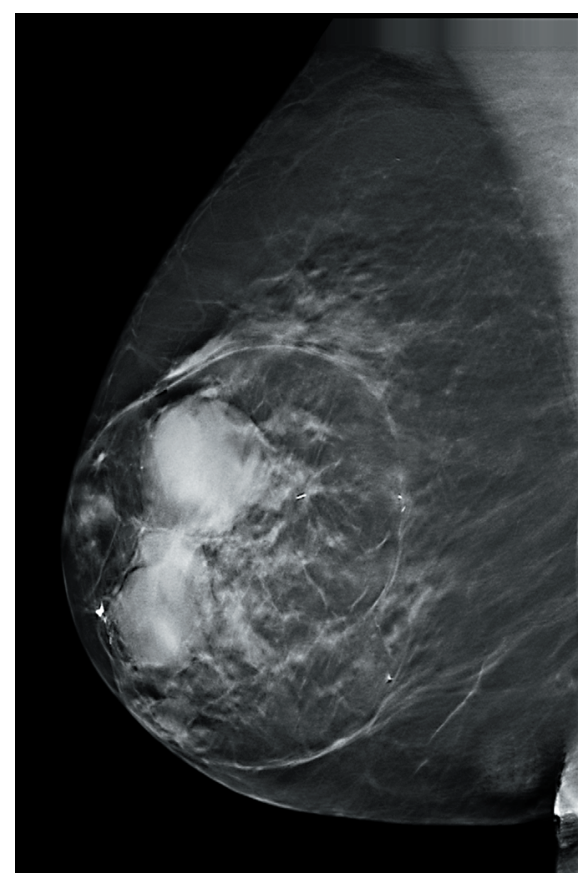

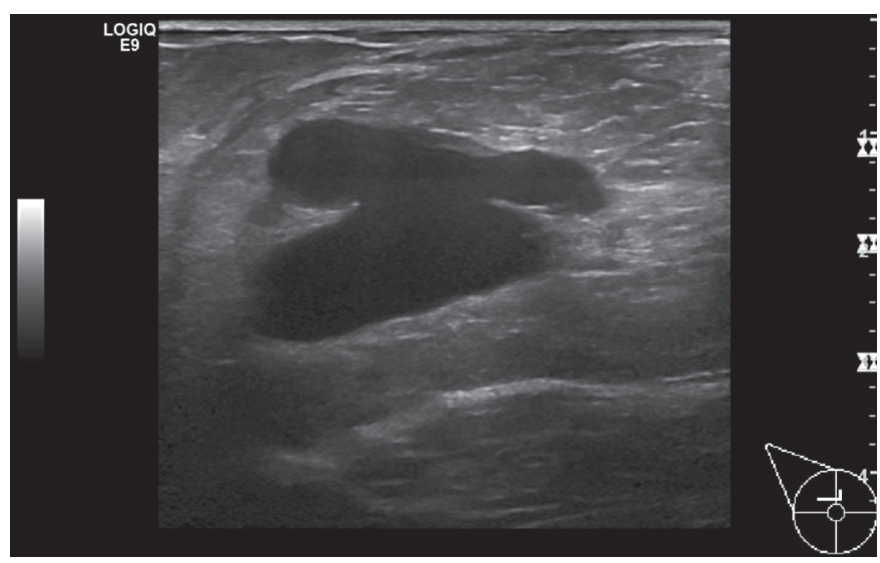

Fig. 6. Hamartoma - mammographic findings.

Fig. 7. Hamartoma - sonographic findings.

as 'enucleation of the phyllodes tumour') results in high local recurrence rates regardless of the histological type. Should a diagnosis of phyllodes tumour be established preoperatively, wide excision should be performed with tumour-free margins of at least $1 \mathrm{~cm}$ from the normal breast tissue, especially in the case of borderline and malignant tumour forms [98-104].

However, should the histological picture of a preoperative biopsy not conform with the diagnostic imaging, it is recommended that an open biopsy be initially carried out. It is generally recommended that an annual follow-up with ultrasound examination should be carried out [39].

\section{Benign Mesenchymal Tumours}

\section{Hamartoma}

Hamartomas (the term was introduced by Arrigoni et al. in 1971 [105]) are localised overgrowths of fibrous, epithelial, and lipoferous elements that normally have an encapsulated appearance [106] (figs. 6, 7).

\section{Pathogenesis}

The genesis of hamartomas is deemed to be a deformity that occurs during embryonic development in the form of inadequate germ tissue differentiation $[106,107]$.

\section{Summary}

Phyllodes tumours are rare breast neoplasias that only account for $0.3-1 \%$ of all mammary tumours and are mainly occur in middle-aged females. They are classified as being lesions of uncertain biological potential (B3). Up until the late 1970s, mastectomy was the standard surgical procedure for all phyllodes tumours regardless of size and histological type. However, radical surgery did not provide any survival benefits so that conservative surgical methods are used nowadays. A simple intracapsular enucleation (referred to

\section{Terminology}

The histological variants of hamartoma include [106]:

- adenolipoma

- fibrolipoma

- lipofibroadenoma

- cystadenolipoma. 
Clinic

Age at Manifestation, Size, and Frequency

Hamartomas have a predominant manifestation in the perimenopausal age group but may occur at any age. They account for $4.8 \%$ of benign breast tumours [108]. Hamartomas present as round or oval lesions and can reach a diameter of up to $20 \mathrm{~cm}$.

\section{Morphology/Microscopy}

Hamartomas are encapsulated tumours that can display fibrocystic or atrophic changes; there is a frequent occurrence of pseudoangiomatous stromal hyperplasia [108].

\section{Non-Invasive Diagnostics}

Palpation

Hamartomas are frequently asymptomatic and are detected on mammography as an incidental finding. Very large lesions can cause breast deformation.

\section{Mammography}

The majority of hamartomas show a characteristic picture in the mammographic examination so that mammography is deemed to be the preferred diagnostic method. They present as smoothly demarcated masses with a different composition of the fat, glandular, and connective tissue content in quantitative terms. The manifestation of the mammographic density varies and depends on the fat/ parenchyma ratio [109]. The thin pseudocapsule is fully or partially discernible (fig. 6).

\section{Ultrasound}

Ultrasound should only be used for the diagnosis of hamartomas in conjunction with mammographic findings. Breast hamartomas display a wide range of ultrasound features so that ultrasound only plays a minor role in the diagnosis [110]. Frequently, a smoothly demarcated, solid, and poorly echogenic structure with dorsal sound disappearance is discernible (fig. 7).

\section{MRI}

On MRI, hamartomas present as compact fatty tissue with a smoothly demarcated, hypointense border and inner heterogenic uptake as characteristic for breast hamartoma [111].

\section{Minimally Invasive Diagnostics}

$\mathrm{CB}$

$\mathrm{CB}$ is of limited use, especially in cases where clinical and imaging clues do not exist. The existence of connective tissue within the lobuli or a connective tissue and fat content in the stroma, whether with or without pseudoangiomatous changes, should provide the pathologist with grounds for considering the possibility of a hamartoma $[111,112]$.

\section{Therapy}

Lesions with a characteristic appearance and typical clinical features of a classic hamartoma can be subjected to conservative therapy. Should the tumour present atypical characteristics however, e.g., an increase in size or specific symptoms, excision or at least a biopsy are recommended [113-115].

\section{Prognosis}

Hamartomas are benign breast lesions but malignant transformation is possible [116]. The literature describes in situ ductal carcinomas, infiltrating ductal carcinomas, and lobular intraepithelial neoplasias in conjunction with hamartomas [114-117]. Hamartomas do not tend to recur.

\section{Discussion}

Histological evaluation is the most certain diagnostic method for benign breast tumours. According to the S3 Guideline and information gained from the literature analysis, preference is to be given to high-speed biopsy (i.e., CB) in each tumour entity [118]. FNAC should no longer be used as standard.

Only a small amount of information or no information at all could be found in the literature regarding the use of VAB, especially for the very rare tumours; hence, the future significance of this method in the diagnosis of rare benign tumours remains to be seen. In the case of certain tumours such as adenomyoepitheliomas, the use of VAB is recommended before CB [119]. Milk duct papillomas play a special role here as not only standard biopsy methods are used for diagnosis and possibly therapy but also ductoscopy. It can be determined from the literature that intraductal papilloma, phyllodes tumour, neurofibroma, and solitary fibrous tumour are the most frequently occurring tumours with a tendency to transform or metastasise. Whereas there is a trend in the literature toward surgical therapy of all forms of phyllodes tumour (benign, borderline, or malignant), the literature regarding intraductal papillomas continues to point toward a possible follow-up behaviour versus operative therapy [120]. The AGO recommends conservative management of solitary papillomas without any atypical characteristics (if biopsy is conclusive and conforms with the imaging) and the performance of an open biopsy for atypical papillomas.

With regard to solitary fibrous tumours, operative therapy is the preferred method due to the possible malignant potential [121].

A general recommendation for an open biopsy should therefore be made in cases of benign solid tumours of the breast with a known increased tendency to transform and metastasise or an unclear biological behaviour (B3 lesions). This excludes solitary papillomas without atypical characteristics. In the case of all other benign breast tumours, management could be in the form of a conservative procedure with annual ultrasound follow-up examinations after a clinical examination, use of corresponding imaging procedures, and last but not least the performance of a punch biopsy to verify the diagnosis. The indication for an open biopsy is also to be established should the tumour increase in size in the follow-up interval, after recurring discrepancies in the punch or vacuum biopsy results, or at the request of the patient. As an alternative, minimally invasive procedures such as therapeutic VAB, cry- 
oablation, or HIFU are also becoming possible alternatives in the definitive surgical management.

The newer minimally invasive methods show an adequate degree of accuracy and hardly any restrictions in terms of post-interventional cosmetics, so that current requirements of extensive breast imaging can be thoroughly met.

\section{Disclosure Statement}

The authors do not have any conflicts of interest to declare.

\section{References}

1 D’Orsi CJ, Sickles EA, Mendelson EB, et al: ACR BIRADS $^{\circledR}$ Atlas, Breast Imaging Reporting and Data System. Reston, VA, American College of Radiology, 2013.

2 Madjar C, Seabert J, Fisseler-Eckhoff A, et al: Relevance of B3 lesions in breast diagnosis - frequency and therapeutic consequences. Senologie 2018;15:153-159.

3 Warren JC: The surgeon and the pathologist. JAMA 1905;45:149-165.

4 Liberman L, Bracero N, Vuolo MA, et al: Percutaneous large-core biopsy of papillary breast lesions. AJR Am J Roentgenol 1999;172:331-337.

5 Gutman H, Schachter J, Wasserberg N, et al: Are solitary breast papillomas entirely benign? Arch Surg 2003;138:1330-1333.

6 Al Sarakbi W, Worku D, Escobar PF, Mokbel K: Breast papillomas: current management with a focus on a new diagnostic and therapeutic modality. Int Semin Surg Oncol 2006;3:1-8.

7 Ohuchi N, Abe R, Takahashi T, Tezuka F: Origin and extension of intraductal papillomas of the breast: a three-dimensional reconstruction study. Breast Cancer Res Treat 1984;4:117-128.

8 Guray M, Sahin AA: Benign breast diseases: classification, diagnosis, and management. Oncologist 2006;11: 435-449.

9 Rosen PP, Holmes G, Lesser ML, et al: Juvenile papillomatosis and breast carcinoma. Cancer 1985;55:1345 1352.

10 Bazzocchi F, Santini D, Martinelli G, et al: Juvenile papillomatosis (epitheliosis) of the breast. A clinical and pathologic study of 13 cases. Am J Clin Pathol 1986;86:745-748.

11 Muttarak M, Lerttumnongtum P, Chaiwun B, Peh WC: Spectrum of papillary lesions of the breast: clinical, imaging and pathologic correlation. AJR Am J Roentgenol 2008;191:700-707.

12 Carter D: Intraductal papillary tumors of the breast: a study of 78 cases. Cancer 1977;39:1689-1692.

13 Woods ER, Helvie MA, Ikeda DM, et al: Solitary breast papilloma: comparison of mammographic, galactographic, and pathologic findings. AJR Am J Roentgenol 1992;159:487-491.

14 Cardenosa G, Eklund GW: Benign papillary neoplasms of the breast: mammographic findings. Radiology 1991;181:751-755.

15 Piccoli CW, Feig SA, Vala MA: Breast imaging case of the day. Benign intraductal papilloma with focal atypical papillomatous hyperplasia. Radiographics 1998;18: 783-786.

16 Ganesan S, Karthik G, Joshi M, Damodaran V: Ultrasound spectrum in intraductal papillary neoplasms of breast. Br J Radiol 2006;79:843-849.

17 Han BK, Choe YH, Ko YH, et al: Benign papillary lesions of the breast: sonographic-pathologic correlation. J Ultrasound Med 1999;18:217-223.

18 Choi JJ, Kang BJ, Kim SH, et al: Role of sonographicelastography in the differential diagnosis of papillary lesions in breast. Jpn J Radiol 2012;30:422-429.

19 Daniel BL, Gardner RW, Birdwell RL, et al: Magnetic resonance imaging of intraductal papilloma of the breast. Magn Reson Imaging 2003;21:887-892.
20 Mokbel K, Elkak AE: Magnetic resonance imaging for screening of woman at high risk for hereditary breast cancer. J Clin Oncol 2001;19:4184.

21 Son EJ, Kim EK, Kim JA, et al: Diagnostic value of 3D fast low-angle shot dynamic MRI of breast papillomas. Yonsei Med J 2009;50:838-844.

22 Lee AHS (ed), Carder P, Deb R, et al: Guidelines for Non-Operative Diagnostic Procedures and Reporting in Breast Cancer Screening. London, The Royal College of Pathologists, 2016, pp.18-24.

23 Amendoeira I, Apostolikas N, Bellocq JP, Wells CA: Quality assurance guidelines for pathology. Cytological and histological non-operative procedures, in Perry N, Broeders M, de Wolf C, et al. (eds): European Guidelines for Quality Assurance in Breast Cancer Screening and Diagnosis. Luxembourg, Office for Official Publications of the European Communities, 2006, pp. 221-255.

24 Leithner D, Kaltenbach B, Hödl P, et al: Intraductal papilloma without atypia on image-guided breast biopsy: upgrade rates to carcinoma at surgical excision. Breast Care (Basel) 2018;13:364-368.

25 Bekes I, deGregorio A, deWaal A, et al: Review on current treatment options for lesions of uncertain malignant potential (B3 lesions) of the breast: do B3 papillary lesions need to be removed in any case by open surgery? Arch Gynecol Obstet 2018;DOI: 10.1007/ s00404-018-4985-0.

26 Rosen EL, Bentley RC, Baker JA, Soo MS: Imagingguided core needle biopsy of papillary lesions of the breast. AJR Am J Roentgenol 2002;179:1185-1192.

27 Philpotts LE, Shaheen NA, Jain KS, et al: Uncommon high-risk lesions of the breast diagnosed at stereotactic core-needle biopsy: clinical importance. Radiology 2000;216:831-837.

28 Agoff SN, Lawton TJ: Papillary lesions of the breast with and without atypical ductal hyperplasia: can we accurately predict benign behaviour from core needle biopsy? Am J Clin Pathol 2004;122:440-443.

29 Sydnor MK, Wilson JD, Hijaz TA, et al: Underestimation of the presence of breast carcinoma in papillary lesions initially diagnosed at core-needle biopsy. Radiology 2007;242:58-62.

30 Renshaw AA, Derhagopian RP, Tizol-Blanco DM, Gould EW: Papillomas and atypical papillomas in breast core needle biopsy specimens: risk of carcinoma in subsequent excision. Am J Clin Pathol 2004;122: 217-221.

31 Rizzo M, Lund MJ, Oprea G, et al: Surgical follow-up and clinical presentation of 142 breast papillary lesions diagnosed by ultrasound-guided core-needle biopsy. Ann Surg Oncol 2008;15:1040-1047.

32 Dennis MA, Parker S, Kaske TI, et al: Incidental treatment of nipple discharge caused by benign intraductal papilloma through diagnostic Mammotome biopsy. AJR Am J Roentgenol 2000;174:1263-1268.

33 Ohlinger R, Grunwald S: Duktoskopie: Lehratlas zur endoskopischen Milchgangsspiegelung; in Römer T, Ebert AD (eds): Frauenärztliche Taschenbücher. Berlin, New York, Walter de Gruyter, 2009, pp. 13-488.

34 Mokbel K, Escobar PF, Matsunaga T: Mammary ductoscopy: current status and future prospects. Eur J Sur Oncol 2005;31:3-8.
5 Dietz JR, Crowe JP, Grundfest S, et al: Directed duct excision by using mammary ductoscopy in patients with pathologic nipple discharge. Surgery 2002;132: 582-588.

36 Shen KW, Wu J, Lu JS, et al: Fiberoptic ductoscopy for breast cancer patients with nipple discharge. Surg Endosc 2001;15:1340-1345.

37 Matsunaga T, Kawakami Y, Namba K, Fujii M: Intraductal biopsy for diagnosis and treatment of intraductal lesions of the breast. Cancer 2004;101:21642169.

38 Liedtke C, Jackisch C, Thill M, et al: AGO recommendations for the diagnosis and treatment of patients with early breast cancer: update 2018. Breast Care (Basel) 2018;13:196-208.

39 Kiaer HW, Kiaer WW, Linell F, Jacobsen S: Extreme duct papillomatosis of the juvenile breast. Acta Pathol Microbiol Scand 1979;87:353-359.

40 Ohlinger R, Schwesinger G, Schimming A, et al: Juvenile papillomatosis (JP) of the female breast (Swiss cheese disease) - role of breast ultrasonography. Ultraschall in Med 2005;26:42-45.

41 Cooper A: Illustrations of the diseases of the female breast. Edinburgh Medical and Surgical Journal 1829; 32:17-18.

42 Tan PH, Tse G, Lee A, et al: Fibroepithelial tumours; in Lakhani SR, Ellis IO, Schnitt SJ, et al (eds): WHO Classification of Tumours of the Breast, ed 4 Lyon, IARC, 2012, pp. 142-147.

43 Dent DM, Cant PJ: Fibroadenoma. World J Surg 1989; 13:706-710.

44 Remmele W (ed), Bässler R, Dallenbach-Hellweg G, et al: Pathologie 4: Weibliches Genitale. Mamma. Pathologie der Schwangerschaft, der Plazenta und des Neugeborenen. Infektionskrankheiten des Fetus und des Neugeborenen. Tumoren des Kindesalters. Endokrine Organe. Berlin, Springer, 1997, pp. 209-212.

45 Liu XF, Zhang JX, Zhou Q, et al: A clinical study on the resection of breast fibroadenoma using two types of incision. Scand J Surg 2011;100:147-152.

46 Pistolese CA, Tosti D, Citraro D, et al: Probably benign breast nodular lesions (BI-RADS 3): correlation between ultrasound features and histologic findings. Ultrasound Med Biol 2018;DOI: 10.1016/j.ultrasmedbio.2018.09.004.

47 Bottles K, Chan JS, Holly EA, et al: Cytologic criteria for fibroadenoma. A step-wise logistic regression analysis. Am J Clin Pathol 1988;89:707-713.

48 Heywang-Köbrunner S, Schreer I (eds): Bildgebende Mammadiagnostik: Untersuchungstechnik, Befundmuster, Differenzialdiagnose und Interventionen. Stuttgart, Georg Thieme, 2015, pp. 292-360.

49 Stavros AT, Rapp CL, Parker SH: Breast Ultrasound. Philadelphia, PA, Lippincott Williams \& Wilkins, 2004, p. 1015.

50 Kuijper A, Mommers EC, van der Wall E, van Diest PJ: Histopathology of fibroadenoma of the breast. Am J Clin Pathol 2001;115:736-742.

51 Mathew J, Crawford DJ, Lwin M, et al: Ultrasoundguided, vacuum-assisted excision in the diagnosis and treatment of clinically benign breast lesions. Ann R Coll Surg Engl 2007;89:494-496. 
52 Lakoma A, Kim ES: Minimally invasive surgical management of benign breast lesions. Gland Surgery 2014; 3:142-148.

53 Greenberg R, Skornick Y, Kaplan O: Management of breast fibroadenomas. J Gen Intern Med 1998;13:640645.

54 Haagensen CD: Disease of the Breast. Philadelphia, PA, W.B. Saunders, 1996, pp. 267-283.

55 Pruthi S, Jones KN: Nonsurgical management of fibroadenoma and virginal breast hypertrophy. Semin Plast Surg 2013;27:62-66.

56 Vlastos G, Verkooijen HM: Minimally invasive approaches for diagnosis and treatment of early-stage breast cancer. Oncologist 2007;12:1-10.

57 Luo HJ, Chen X, Tu G, et al: Therapeutic application of ultrasound-guided 8-gauge Mammotome system in presumed benign breast lesions. Breast J 2011;17:490497.

58 Littrup PJ, Freeman-Gibb L, Andea A, et al: Cryotherapy for breast fibroadenomas. Radiology 2005;234:6372.

59 Kaufman CS, Littrup PJ, Freeman-Gibb LA, et al: Office-based cryoablation of breast fibroadenomas with long-term follow-up. Breast J 2005; 11:344-350.

60 Hahn M, Pavlista D, Danes J, et al: Ultrasound guided cryoablation of fibroadenomas. Utraschall Med 2013; 34:64-68.

61 Bland KL, Gass J, Klimberg VS: Radiofrequency, cryoablation, and other modalities for breast cancer ablation. Surg Clin North Am 2007;87:539-550.

62 Mahnken AH, König AM, Figiel JH: Current technique and application of percutaneous cryotherapy. Rofo 2018;190:836-846.

63 Papathemelis T, Heim S, Lux MP, et al: Minimally invasive breast fibroadenoma excision using an ultrasound-guided vacuum-assisted biopsy device. Geburtshilfe Frauenheilkd 2017;77:176-181.

64 Dupont WD, Page DL, Parl FF, et al: Long-term risk of breast cancer in women with fibroadenoma. N Engl J Med 1994;331:10-15.

65 Pacchiarotti A, Selman H, Gentile V, et al: First case of transformation for breast fibroadenoma to high-grade malignant phyllodes tumor in an in vitro fertilization patient: misdiagnosis of recurrence, treatment and review of the literature. Eur Rev Med Pharmacol Sci 2013;17:2495-2498.

66 Abe M, Miyata S, Nishimura S, et al: Malignant transformation of breast fibroadenoma to malignant phyllodes tumor: long-term outcome of 36 malignant phyllodes tumors. Breast Cancer 2011;18:268-272.

67 Greenberg R, Skornick Y, Kaplan O: Management of breast fibroadenomas. J Gen Intern Med 1998;13:640-645.

68 Levi F, Randimbison L, Te VC, La Vecchia C: Incidence of breast cancer in women with fibroadenoma. Int J Cancer 1994;57:681-683.

69 Müller J: Ueber den feinern Bau und die Formen der krankhaften Geschwülste. Berlin, Reimer G (ed), 1838, pp. 54-60.

70 Rosewell MD, Perry RR, Hsju JG, Barranco SC: Phyllodes tumors. Am J Surg 1983;165:376-379.

71 Komenaka IK, El-Tamer M, Pile-Spellman E, Hibshoosh $\mathrm{H}$ : Core needle biopsy as a diagnostic tool to differentiate phyllodes tumor from fibroadenoma. Arch Surg 2003;138:987-990.

72 International histological classification of tumours: histologic types of breast tumours. Geneva, WHO, 1981

73 Tavassoli FA: Pathology of the Breast, ed 2. New York, NY, McGraw-Hill Professional, 1999, p. 573.

74 Elston CW, Ellis IO: Fibroadenoma and related conditions; in Elston CW, Ellis IO (eds): The Breast. Edin burgh, Churchill Livingstone, 1998.

75 Parker SJ, Harries SA: Phyllodes tumours. Postgrad Med J 2001;77:428-435.
6 Fernandez BB, Hernandez FJ, Spindler W: Metastatic cystosarcoma phyllodes, a light and electron microscopic study. Cancer 1976;37:1737-1746.

77 Al-Masri M, Darwazeh G, Sawalhi S, et al: Phyllodes tumor of the breast: role of CD10 in predicting metastasis. Ann Surg Oncol 2011;19:1181-1184.

78 Aranda FI, Laforga JB, Lopez JL: Phyllodes tumor of the breast. An immunhistochemical study of 28 cases with special attention to the role of myofibroblast. Pathol Res Pract 1994;190:474-481.

79 Jacklin RK, Ridgway PF, Ziprin P, et al: Optimising preoperative diagnosis in phyllodes tumour of the breast. J Clin Pathol 2006;59:454-459.

80 Chua CL, Thomas A, Ng BK: Cystosarcoma phyllodes: a review of surgical options. Surgery 1989;105:141-147.

81 Stebbing JF, Nash AG: Diagnosis and management of phyllodes tumour of the breast: experience of 33 cases at a specialist centre. Ann R Coll Surg Engl 1995;77: 181-184.

82 Umpleby HC, Moore I, Royle GT, et al: An evaluation of the preoperative diagnosis and management of cystosarcoma phyllodes. Ann R Coll Surg Engl 1989;71:285-288.

83 Bartoli C, Zurrida S, Veronesi P, et al: Small sized phyllodes tumor of the breast. Eur J Surg Oncol 1990;16: 215-219.

84 Reinfuss M, Mitus J, Duda K, et al: The treatment and prognosis of patients with phyllodes tumor of the breast: an analysis of 170 cases. Cancer 1996;77:910-916.

85 Norris HJ, Taylor HR: Relationship of histological features to behavior of cystosarcoma phyllodes. Cancer 1967;20:2090-2099.

86 Vorherr H, Vorherr UF, Kutvirt DM, Key CR: Cystosarcoma phyllodes: epidemiology, pathohistology, pathobiology, diagnosis, therapy and survival. Arch Gynecol 1985;236:173-181.

87 Buchberger W, Strasser K, Heim K, et al: Phylloides tumor: findings on mammography, sonography and aspiration cytology in 10 cases. AJR Am J Roentgenol 1991;157:715-719.

88 Page JE, Williams JE: The radiological features of phyllodes tumour of the breast with clinico-pathological correlation. Clin Radiol 1991;44:8-12.

89 Goel NB, Knight TE, Pandey S, et al: Fibrous lesions of the breast: imaging-pathologic correlation. Radiographics 2005;25:1547-1559.

90 Balaji R, Ramachandran KN: Magnetic resonance imaging of a benign phyllodes tumor of the breast. Breast Care (Basel) 2009;4:189-191.

91 Patrascu A, Popescu CF, Plesea IE, et al: Clinical and cytopathological aspects in phyllodes tumors of the breast. Rom J Morphol Embryol 2009;50:605-611.

92 Jacklin RK, Ridgway PF, Ziprin P, et al: Optimising preoperative diagnosis in phyllodes tumour of the breast. J Clin Pathol 2006;59:454-459.

93 Ouyang Q, Li S, Tan C, et al: Benign phyllodes tumor of the breast diagnosed after ultrasound-guided vacuum-assisted biopsy: surgical excision or wait-andwatch? Ann Surg Oncol 2016;23:1129-1134

94 Sotheran W, Domjan J, Jeffrey M, et al: Phyllodes tumours of the breast - a retrospective study from 19822000 of 50 cases in Portsmouth. Ann R Coll Surg Engl 2005;87:339-344.

95 Grimes MM: Cystosarcoma phyllodes of the breast: histologic features, flow cytometric analysis, and clini cal correlations. Mod Pathol 1992;5:232-239.

96 Moffat CJ, Pinder SE, Dixon AR, et al: Phyllodes tumours of the breast: a clinico-pathological review of thirty two cases. Histopathology 1995;27:205-218.

97 Barth RJ Jr: Histologic features predict local recurrence after breast conserving therapy of phyllodes tumors. Breast Cancer Res Treat 1999;57:291-295

98 Chen WH, Cheng SP, Tzen CY, et al: Surgical treatment of phyllodes tumors of the breast: retrospective review of 172 cases. J Surg Oncol 2005;91:185-194.
99 Dyer NH, Bridger JE, Taylor RS: Cystosarcoma phylloides. Br J Surg 1966;53:450-455.

100 Maier WP, Rosemond GP, Wittenberg P, Tassoni EM: Cystosarcoma phyllodes mammae. Oncology 1968; 22:145-158.

101 Cohn-Cedermark G, Rutqvist LE, Rosendahl I, Silfverswärd C: Prognostic factors in cystosarcoma phyllodes. A clinicopathologic study of 77 patients. Cancer 1991;68:2017-2022.

102 Contarini O, Urdaneta LF, Hagan W, Stephenson SE Jr: Cystosarcoma phylloides of the breast: a new therapeutic proposal. Am Surg1982;48:157-166.

103 Hajdu SJ, Espinosa MH, Robbins GF: Recurrent cystosarcoma phyllodes: a clinicopathologic study of 32 cases. Cancer 1976;38:1402-1406.

104 Mangi AA, Smith BL, Gadd MA, et al: Surgical management of phyllodes tumors. Arch Surg 1999;134: 487-492.

105 Arragoni MG, Dockerty MB, Judd ES: The identification and treatment of mammary hamartoma. Surg Gynecol Obstet 1971;133:577-582.

106 Choi N, Ko ES: Invasive ductal carcinoma in a mammary hamartoma: case report and review of the literature. Korean J Radiol 2010;11:687-691.

107 Lanyi M: Brustkrankheiten im Mammogramm. Berlin, Springer, 2003, pp. 60-64.

108 Schrager CA, Schneider D, Gruener AC, et al: Clinical and pathological features of breast disease in Cowden's syndrome: an under recognized syndrome with an increased risk of breast cancer. Hum Pathol 1998;29:47-53.

109 Charpin C, Mathoulin MP, Andrac L, et al: Reappraisal of breast hamartomas. A morphological study of 41 cases. Pathol Res Pract 1994;190:362-371.

110 Wahner-Roedler DL, Sebo TJ, Gisvold JJ: Hamarto mas of the breast: clinical, radiologic and pathologic manifestations. Breast J 2001;7:101-105

111 Adler DD, Jeffries DO, Helvie MA: Sonographic features of breast hamartomas. J Ultrasound Med 1990. 9:85-90.

112 Tse GM, Law BK, Ma TK, et al: Hamartoma of the breast: a clinicopathological review. J Clin Pathol 2002;55:951-954.

113 Heywang-Köbrunner SH, Heinig A, Hellerhoff K, et al: Use of ultrasound-guided percutaneous vacuum assisted breast biopsy for selected difficult indications. Breast J 2009;15:348-356.

114 Mester J, Simmons RM, Vazquez MF, Rosenblatt R: In situ and infiltrating ductal carcinoma arising in a breast hamartoma. AJR Am J Roentgenol 2000;175:64-66.

115 Anani PA, Hessler C: Breast hamartoma with invasive ductal carcinoma. Report of two cases and review of the literature. Pathol Res Pract 1996;192:1187-1194.

116 Barbaros U, Deveci U, Erbil Y, Budak D: Breast hamartoma: a case report. Acta Chir Belg 2005;105: 658-659.

117 Coyne J, Hobbs FM, Boggis C, Harland R: Lobular carcinoma in a mammary hamartoma. J ClinPathol 1992;45:936-937.

118 Albert U-S: Stufe-3-Leitlinie Brustkrebs-Früherkennung in Deutschland. München-Wien-New York, W. Zuckschwerdt, 2008, pp. 1-353.

119 Yahara T, Yamaguchi R, Yokoyama G, et al: Adenomyoepithelioma of the breast diagnosed by a mammotome biopsy: report of a case. Surg Today 2008; 38:144-146.

120 Rozentsvayg E, Carver K, Borkar S, et al: Surgical excision of benign papillomas diagnosed with core biopsy: a community hospital approach. Radiol Res Pract Epub 2011:1-4.

121 Van Kints MJ, Tham RT, Klinkhamer PJ, van den Bosch HC: Hemangiopericytoma of the breast: mammographic and sonographic findings. AJR Am J Roentgenol 1994;163:61-63. 